\title{
Late Recurrence of Hepatocellular Carcinoma after Liver Transplantation
}

\author{
Kenneth S. H. Chok • See Ching Chan • \\ Tan To Cheung $\cdot$ Albert C. Y. Chan • \\ Sheung Tat Fan $\cdot$ Chung Mau Lo
}

Published online: 20 May 2011

(c) The Author(s) 2011. This article is published with open access at Springerlink.com

\begin{abstract}
Background Long-term survival of patients with hepatocellular carcinoma (HCC) after liver transplantation is affected mainly by recurrence of HCC. There is the opinion that the chance of recurrence after 2 years post-transplantation is remote, and therefore lifelong surveillance is not justified because of limited resources. The aims of the present study were to determine the rate of late HCC recurrence ( $\geq 2$ years after transplantation) and to compare the long-term patient survival outcomes between cases of early recurrence $(<2$ years after transplantation) and late recurrence.

Patients A total of 139 adult HCC patients having liver transplantation during the period from July 1994 to December 2007 were included in the analysis. The median follow-up period was 55 months. Thirty-two patients received deceased-donor grafts and 107 received livingdonor grafts.

Results Hepatocellular carcinoma recurrence occurred in $24(17.3 \%)$ patients, among them $22(86 \%)$ had livingdonor grafts and 7 (5\%) developed late recurrence. Patients in the early recurrence group and patients in the late
\end{abstract}

K. S. H. Chok $(\bowtie) \cdot$ S. C. Chan · T. T. Cheung

A. C. Y. Chan - S. T. Fan - C. M. Lo

Department of Surgery, The University of Hong Kong,

102 Pokfulam Road, Hong Kong, SAR,

People's Republic of China

e-mail: kennethchok@yahoo.com.hk

S. C. Chan · S. T. Fan - C. M. Lo

State Key Laboratory for Liver Research,

The University of Hong Kong, 102 Pokfulam Road,

Hong Kong, SAR, People's Republic of China recurrence group had comparable demographics and disease pathology. The former group, when compared with the latter, had significantly worse overall survival at 3 years (13.3 versus $100 \%)$ and 5 years (6.67 versus 71.4\%) (log-rank test; $p<0.001)$.

Conclusions Both early recurrence and late recurrence of HCC after liver transplantation were not uncommon, mostly detected at a subclinical stage. Regular and longterm surveillance with imaging and blood tests is essential for early detection.

\section{Introduction}

Hepatocellular carcinoma (HCC) is the leading cause of death in patients with hepatitis $\mathrm{B}$ or $\mathrm{C}$, and its incidence has increased considerably over the past decade [1]. Among various modalities for treating HCC and underlying cirrhosis, liver transplantation (LT) is the ultimate solution. Unfortunately, HCC recurs in $10-60 \%$ of patients after LT [2-6]. The average time for recurrence ranges between 1 and 2 years after LT [2-6]. However, there have been limited studies on late recurrence $\geq 2$ years after LT) of HCC, and its occurrence is poorly understood. The present study was designed to determine the rate of late HCC recurrence and to compare the long-term patient survival outcomes between cases of early recurrence $(<2$ years after LT) and late recurrence.

\section{Patients and methods}

Data of all adult HCC patients who underwent LT, with deceased donor or living donor, at Department of Surgery, Queen Mary Hospital, Hong Kong, China, in the period 
from July 1994 to December 2007 were reviewed. The strategies adopted for selection and management of patients with known HCC for LT have been described elsewhere [7]. In brief, only patients aged 65 years or below with disease not amenable to partial hepatectomy and local ablation were considered for LT. Before 2002, the radiological Milan criteria [2] (solitary tumor up to $5 \mathrm{~cm}$ in size, or a maximum of 3 tumor nodules with each no larger than $3 \mathrm{~cm}$ ) were observed in selection of patients. Since 2002, the tumor number and size limits have been expanded to match the criteria of University of California, San Francisco (UCSF criteria) [8] (solitary tumor not exceeding $6.5 \mathrm{~cm}$, or a maximum of three tumor nodules totaling up to $8 \mathrm{~cm}$ in diameter with each nodule no bigger than $4.5 \mathrm{~cm}$ ). Tumor evaluation was done with computed tomography of the abdomen and thorax, in addition to radionuclide bone scan at initial diagnosis. In recent years dual-tracer $\left[{ }^{11} \mathrm{C}\right.$-acetate and ${ }^{18}$ F-fluorodeoxyglucose (FDG)] positron emission tomography was occasionally performed on selected patients to exclude extrahepatic metastasis. Imaging was repeated every 3-6 months for patients with prolonged waiting time, and transarterial lipiodol chemoembolization was given to patients with adequate liver reserve to contain tumor growth. Patients whose tumors progressed to beyond the acceptance criteria as shown by serial imaging were excluded from transplantation. Also excluded were patients who had major vascular invasion or extrahepatic diseases.

All living liver graft donors must have compatible $\mathrm{ABO}$ blood group, serology negative of hepatitis B surface antigen and hepatitis $\mathrm{C}$ antibody, and no evidence of any acute or chronic illness that would increase operation risk. Computed tomography with volumetry was performed to determine the size of the donor liver, and left-lobe graft or right-lobe graft was decided with the principle that the graft must be larger than $40 \%$ of the recipient's standard liver weight [9] as estimated according to the Urata formula [10].

Hospital mortality was defined as death occurring during the hospital admission for the primary operation. Patients were followed up at the outpatient clinic weekly within the first 3 months after operation, and afterwards every 1-3 months, depending on clinical status and results of liver function tests. Routine blood tests, including hepatic and renal function tests, were carried out in every followup visit. Serum $\alpha$-fetoprotein check, chest X-ray, and computed tomography (or magnetic resonance imaging for patients with impaired renal function) were performed every 3-6 months during the first 5 years after operation. After 5 years, imaging was done every 6 months- 1 year or when deemed indicated (e.g., serum $\alpha$-fetoprotein level showing a rising trend).

\section{Statistical analysis}

Comparison of categorical variables was performed using a chi-square test or Fisher's exact test where appropriate. Nonparametric continuous variables were compared with the Mann-Whitney $U$-test and presented as medians with range. Parametric continuous variables were compared with Student's $t$-test and presented as means with standard deviation. Survival was analyzed with the Kaplan-Meier method, and comparison of variables was performed using the log-rank test. All $p$ values less than 0.05 were regarded as statistically significant, and all $p$ values were two-tailed.

\section{Results}

A total of 139 patients, 119 male and 20 female, were included for analysis. Among them, 115 patients had no recurrence of $\mathrm{HCC}, 17$ patients had early recurrence, and 7 patients had late recurrence. The early recurrence group and the late recurrence group had comparable demographics and disease pathology (Table 1). Two patients developed very late recurrence ( $>5$ years after LT). One of them had recurrence in the left adrenal gland 5.2 years after LT, and was treated with laparoscopic adrenalectomy. She remained free of disease for 1 year until a recent computed tomography scan revealed a $1 \mathrm{~cm}$ intrahepatic recurrence, which was treated with percutaneous radiofrequency ablation. She has been free of disease since then. The other patient had recurrence in the retrocaval lymph node 6.5 years after LT. The recurrence was deemed unresectable because there was tumor thrombus inside the inferior vena cava. Treatments for other patients' recurrence are listed in Table 2. All surgical specimens were sent for histopathologic examination and were confirmed to be metastatic HCC. The early recurrence group, when compared with the late recurrence group, had significantly poorer overall survival (Fig. 1). The former had overall survival at 1, 3, and 5 years at 100, 13.3, and $6.67 \%$, respectively, and the latter had 100, 100, and $71.4 \%$, respectively (Table 3). Similarly, survival after recurrence was also poorer in the early recurrence group, although it did not reach statistical significance (Fig. 2).

\section{Discussion}

The tumor recurrence rate in this study was $17.3 \%$ (24/ $139)$, which is not uncommon. Late recurrence occurred in $5 \%(7 / 139)$ of patients; 2 patients even developed recurrence after 5 years of LT. All recurrences were found at a subclinical stage, and this demonstrates the importance of regular surveillance as early intervention may prolong 
Table 1 Demographic and pathologic data of the two groups
$L T$ liver transplant, $H B V$ hepatitis B virus, $H C V$ hepatitis $\mathrm{C}$ virus, UCSF University of California San Francisco

${ }^{a}$ One patient in the early recurrence group had no viable tumor on histopathology after transarterial chemoembolization

\begin{tabular}{|c|c|c|c|}
\hline & $\begin{array}{l}\text { Early recurrence } \\
(n=17)\end{array}$ & $\begin{array}{l}\text { Late recurrence } \\
(n=7)\end{array}$ & $p$ value \\
\hline Sex (male:female) & $17: 0$ & $6: 1$ & 0.292 \\
\hline Median age, years (range) & $47(40-61)$ & $52(41-56)$ & 0.292 \\
\hline Deceased-donor LT:living-donor LT & $1: 16$ & $1: 6$ & 0.507 \\
\hline HBV carrier & 17 & 7 & \\
\hline $\mathrm{HCV}$ carrier & 0 & 0 & \\
\hline $\mathrm{HBV}$ and $\mathrm{HCV}$ co-infection & 0 & 0 & \\
\hline $\begin{array}{l}\text { Median preoperative } \alpha \text {-fetoprotein, } \mathrm{ng} / \mathrm{ml} \\
\text { (range) }\end{array}$ & $84(4-117,850)$ & $411(3-975)$ & 0.391 \\
\hline \multicolumn{4}{|l|}{ Pretransplant treatment } \\
\hline No treatment & 4 & 3 & \\
\hline Transarterial chemoembolization & 6 & 2 & \\
\hline Ethanol injection & 0 & 0 & \\
\hline Hepatectomy & 5 & 2 & \\
\hline Chemotherapy & 1 & 0 & \\
\hline Radiofrequency ablation & 5 & 1 & \\
\hline \multicolumn{4}{|l|}{ Pretransplant anti-HBV therapy } \\
\hline Lamivudine & 13 & 5 & \\
\hline Lamivudine + adefovir & 1 & 2 & \\
\hline Entecavir & 2 & 0 & \\
\hline Lamivudine + Tenofovir & 0 & 0 & \\
\hline Lamivudine + Adefovir + Entecavir & 1 & 0 & \\
\hline HBV-DNA positivity at study end point (\%) & $8(47.1)$ & $1(14.3)$ & 0.002 \\
\hline HBV mutant detected at study end point $(\%)$ & $4(23.5)$ & $2(28.6)$ & 0.900 \\
\hline Salvage transplantation $(\%)$ & $9(52.9)$ & $3(42.9)$ & 1.000 \\
\hline Explant pathology (no. of tumors) ${ }^{a}$ & & & 0.998 \\
\hline 1 & 7 & 3 & \\
\hline 2 & 2 & 1 & \\
\hline 3 & 2 & 1 & \\
\hline$\geq 4$ & 5 & 2 & \\
\hline Median largest tumor size, $\mathrm{cm}$ (range) & $3.6(1.5-19.5)$ & $2.5(1.0-7.5)$ & 0.482 \\
\hline Presence of microvascular permeation (\%) & $11(64.7)$ & $3(42.9)$ & 0.393 \\
\hline TNM staging 2003 & & & 0.133 \\
\hline $\mathrm{I}(\%)$ & $3(17.6)$ & $3(42.9)$ & \\
\hline II $(\%)$ & $10(58.8)$ & $1(14.3)$ & \\
\hline IIIA (\%) & $4(23.5)$ & $3(42.9)$ & \\
\hline IIIB (\%) & $0(0)$ & $0(0)$ & \\
\hline Within Milan criteria & 7 & 4 & 0.659 \\
\hline Beyond Milan criteria & 10 & 3 & \\
\hline Within UCSF criteria & 9 & 4 & 1.000 \\
\hline Beyond UCSF criteria & 8 & 3 & \\
\hline
\end{tabular}

Late recurrence of HCC after LT was quite common in this study. As noted by Poon [13], a strict surveillance program monitoring recurrence should be adopted before any recommendation can be made with a large cohort. After all, current evidence is suboptimal. It was showed that viral load of hepatitis B may be an important risk factor for late recurrence after resection [14]. However, all the patients in this study were on some sort of antiviral 
Table 2 Treatments of recurrences in the two groups

\begin{tabular}{|c|c|c|}
\hline Treatment $^{\mathrm{a}}$ & $\begin{array}{l}\text { Early recurrence } \\
(n=17)\end{array}$ & $\begin{array}{l}\text { Late recurrence } \\
(n=7)\end{array}$ \\
\hline \multicolumn{3}{|l|}{ Intrahepatic recurrence } \\
\hline Hepatectomy & 2 & 0 \\
\hline $\begin{array}{l}\text { Transarterial } \\
\text { chemoembolization }\end{array}$ & 4 & 1 \\
\hline Radiofrequency ablation & 3 & 1 \\
\hline \multicolumn{3}{|l|}{ Extrahepatic recurrence } \\
\hline Adrenalectomy & 1 & 1 \\
\hline Lung resection & 6 & 0 \\
\hline $\begin{array}{l}\text { Excision of solitary peritoneal } \\
\text { metastasis }\end{array}$ & 0 & 1 \\
\hline $\begin{array}{l}\text { Excision of retrocaval lymph } \\
\text { node }\end{array}$ & 0 & 1 \\
\hline $\begin{array}{l}\text { Excision of inferior vena cava } \\
\text { tumor thrombus }\end{array}$ & 0 & 1 \\
\hline $\begin{array}{l}\text { Excision of common hepatic } \\
\text { artery lymph node }\end{array}$ & 0 & 1 \\
\hline Chemotherapy & 4 & 1 \\
\hline Radiotherapy & 6 & 3 \\
\hline Interferon & 3 & 0 \\
\hline Tamoxifen & 0 & 1 \\
\hline Sorafenib & 5 & 0 \\
\hline Xeloda & 1 & 1 \\
\hline $\begin{array}{l}\text { Nailing and plating of bone } \\
\text { metastasis }\end{array}$ & 2 & 1 \\
\hline
\end{tabular}

${ }^{a}$ A patient might receive more than one treatment modality

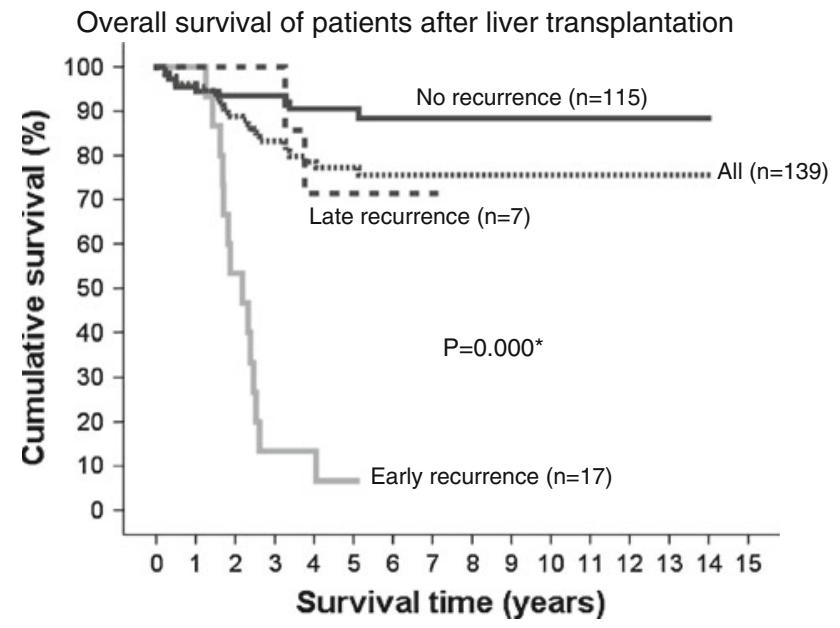

Fig. 1 Overall survival of patients after liver transplantation

therapy before LT surgery, and hepatitis B surface antigen positivity was similar in the two recurrence groups. So, at least in this study, the role of viral load might not have been too significant in recurrence.

In Western countries, $\mathrm{HCC}$ is mainly caused by $\mathrm{HCV}$ infection, but in our locality, HBV infection is the main
Table 3 Postoperative outcomes in the two groups

\begin{tabular}{llll}
\hline & $\begin{array}{l}\text { Early } \\
\text { recurrence } \\
(n=17)\end{array}$ & $\begin{array}{l}\text { Late } \\
\text { recurrence } \\
(n=7)\end{array}$ & $p$ value \\
\hline Latest HBsAg in HBV patients & & & 0.393 \\
$\quad$ Negative & 11 & 3 & \\
Positive & 6 & 4 & 0.611 \\
History of rejection & $3(17.6 \%)$ & 0 & 0.665 \\
Latest immunosuppression & & & \\
FK 506 & 8 & 5 & \\
Sirolimus & 7 & 2 & 0.001 \\
FK 506 + prednisolone & 1 & 0 & \\
FK 506 + sirolimus & 1 & 0 & \\
Hospital mortality (\%) & $0(0)$ & $0(0)$ & \\
Patient overall survival & & 100 & \\
1 year $(\%)$ & 100 & 100 & \\
3 years $(\%)$ & 13.3 & 71.4 & \\
5 years (\%) & 6.67 &
\end{tabular}

HBsAg hepatitis B surface antigen

${ }^{a}$ No HBV serology checked before death

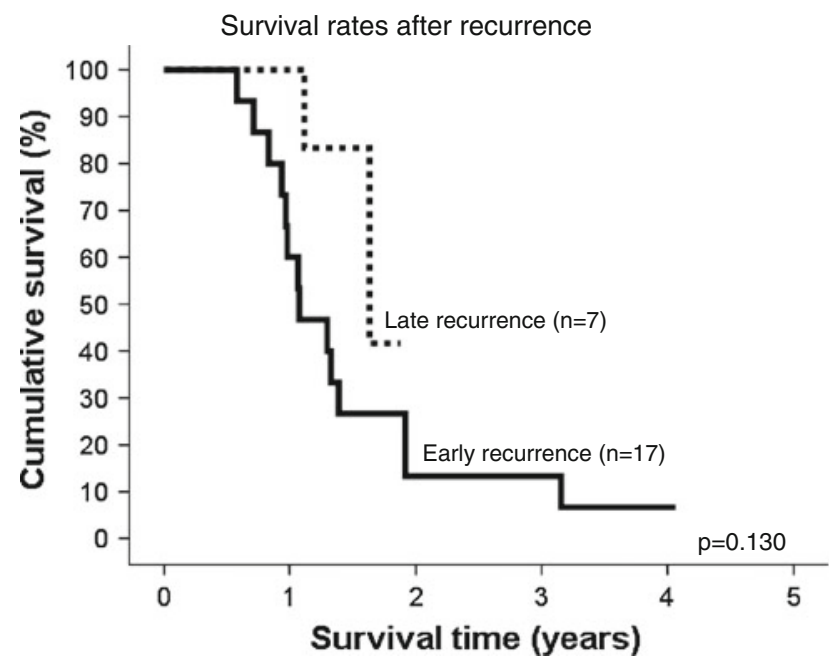

Fig. 2 Survival rates after recurrence

cause. Although effective treatments for HBV infection are available, recurrence of HCC is still common. To decrease the rate of HCC recurrence, further adjuvant treatments for high-risk patients have to be developed.

Notoriously, HCC recurrence after LT carries very poor prognosis in the presence of the effects of immunosuppression. An early report suggested that recurrent HCC after transplantation has a more aggressive course than recurrent HCC after resection, presumably because of immunosuppression [15]. Nonetheless, our center adopts an aggressive approach in managing patients with recurrence after LT, and treatments include resection and 
ablation. In addition, decreasing dosage of immunosuppressants may help to hinder the progression of disease. Recently, medications have been used on high-risk patients. Sirolimus is an inhibitor of mTOR and is used as an immunosuppressive medication on patients who are at high risk of tumor recurrence after LT. Sorafenib (Nexavar, Bayer HealthCare, Wayne, NJ) is a multi-kinase inhibitor approved for the treatment of advanced HCC. A recent study reported that the combination use of sirolimus and sorafenib appeared to have a synergistic effect in treating recurrent HCC after LT [16]. For the time-being, there is no well-established protocol on the use of sorafenib at our center. In general, it is prescribed mainly to patients with widespread extrahepatic diseases. For patients with solitary extrahepatic metastasis or intrahepatic recurrence, resection or ablation is the treatment of choice. Further research on the efficacy of these medications, used solely or in combination, will certainly contribute to the management of recurrent HCC after LT.

In conclusion, early and late recurrences of $\mathrm{HCC}$ after LT are not uncommon and can be detected at a subclinical stage with regular monitoring. Long-term surveillance with imaging and blood tests is essential for early detection.

Open Access This article is distributed under the terms of the Creative Commons Attribution Noncommercial License which permits any noncommercial use, distribution, and reproduction in any medium, provided the original author(s) and source are credited.

\section{References}

1. El-Serag HB, Mason AC (1999) Rising incidence of hepatocellular carcinoma in the United States. N Engl J Med 340:745-750

2. Mazzaferro V, Regalia E, Doci R et al (1996) Liver transplantation for the treatment of small hepatocellular carcinoma in patients with cirrhosis. N Engl J Med 334:693-699
3. Roayaie S, Schwartz JD, Sung MW et al (2004) Recurrence of hepatocellular carcinoma after liver transplant: patterns and prognosis. Liver Transpl 10:534-540

4. Regalia E, Fassati LR, Valente U et al (1998) Pattern and management of recurrent hepatocelluar carcinoma after liver transplantation. J Hepatobiliary Pancreat Surg 5:29-34

5. Merli M, Nicolini G, Gentili F et al (2005) Predictive factors of outcome after liver transplantation in patients with cirrhosis and hepatocellular carcinoma. Transplant Proc 37:2535-2540

6. Schlitt HJ, Neipp M, Weimann A et al (1999) Recurrence patterns of hepatocellular and fibrolamellar carcinoma after liver transplantation. J Clin Oncol 17:324-331

7. Lo CM, Fan ST, Liu CL et al (2004) The role and limitation of living donor liver transplantation for hepatocellular carcinoma. Liver Transpl 10:440-447

8. Yao FY, Ferrell L, Bass NM et al (2001) Liver transplantation for hepatocellular carcinoma: expansion of the tumor size limits does not adversely impact survival. Hepatology 33:1394-1403

9. Lo CM, Fan ST, Liu CL et al (1999) Minimum graft size for successful living donor liver transplantation. Transplantation 68: $1112-1116$

10. Urata K, Kawasaki S, Matsunami H et al (1995) Calculation of child and adult standard liver volume for liver transplantation. Hepatology 21:1317-1321

11. Ng DS, Chok KS, Law WL et al (2007) Long-term survival after resection of extrahepatic recurrence of hepatocellular carcinoma at the right colon. Int J Colorectal Dis 22:1411-1412

12. Wong TC, To KF, Hou SS et al (2010) Late retroperitoneal recurrence of hepatocellular carcinoma 12 years after initial diagnosis. World J Gastroenterol 16:2187-2189

13. Poon RT (2009) Differentiating early and late recurrences after resection of HCC in cirrhotic patients: implications on surveillance, prevention, and treatment strategies. Ann Surg Oncol 16: 792-794

14. Wu JC, Huang YH, Chau GY et al (2009) Risk factors for early and late recurrence in hepatitis B-related hepatocellular carcinoma. J Hepatol 51:890-897

15. Yokoyama I, Carr B, Saitsu H et al (1991) Accelerated growth rates of recurrent hepatocellular carcinoma after liver transplantation. Cancer 68:2095-2100

16. Kim R, Aucejo F (2010) Radiologic complete response with sirolimus and sorafenib in a hepatocellular carcinoma patient who relapsed after orthotopic liver transplantation. J Gastrointest Cancer 42:50-53 